\title{
PBC triggers in water reservoirs, coal mining areas and waste disposal sites: From Newcastle to New York
}

\author{
Daniel Smyk $^{\mathrm{a}}$, Maria G. Mytilinaiou ${ }^{\mathrm{a}}$, Eirini I. Rigopoulou ${ }^{\mathrm{b}, \mathrm{c}}$ and Dimitrios P. Bogdanos ${ }^{\mathrm{a}, *}$ \\ ${ }^{a}$ Institute of Liver Studies, King's College London School of Medicine at King's College Hospital, Denmark Hill \\ Campus, London, UK \\ ${ }^{\mathrm{b}}$ Department of Medicine and Research Laboratory of Internal Medicine, Medical School, University of Thessaly, \\ Larissa, Thessaly, Greece \\ ${ }^{\mathrm{c}}$ Institute of Biomedical Research and Technology, Centre for Research and Technology-Thessaly (CE.RE.TE.TH), \\ Larissa, Thessaly, Greece
}

\begin{abstract}
Various environmental factors have been proposed as triggers of primary biliary cirrhosis (PBC), a progressive autoimmune cholestatic liver disease which is characterised by the destruction of the small intrahepatic bile ducts. Support for their pathogenic role in PBC is provided by epidemiological studies reporting familial clustering and clusters of the disease within a given geographical area. The seminal study by Triger reporting that the great majority of PBC cases in the English city of Sheffield drank water from a specific water reservoir, has been followed by studies reporting disease 'hot spots' within a restricted geographic region of the former coal mining area of Newcastle. The New York study reporting an increased risk and significant clustering of PBC cases near toxic federal waste disposal sites has added strength to the notion that environmental factors, possibly in the form of infectious agents or toxic/chemical environmental factors in areas of contaminated land, water or polluted air may play a key role in the development of the disease. This review discusses the findings of reports investigating environmental factors which may contribute to the cause of primary biliary cirrhosis.
\end{abstract}

Keywords: Autoimmunity, disease, bile ducts, cholestasis, liver, immunity, tolerance, mimicry, cross-reactivity, environment

\section{List of abbreviations}

PBC primary biliary cirrhosis

AMA anti-mitochondrial antibody

BEC biliary epithelial cell

OADC oxo-acid dehydrogenase complex

PDC pyruvate dehydrogenase complex

\footnotetext{
* Corresponding author: Dimitrios P. Bogdanos, MD, PhD, Clinical Senior Lecturer/Consultant, Liver Immunopathology \& Liver Immunodiagnostics, Institute of Liver Studies, King's College London Medical School at King's College Hospital, Denmark Hill Campus, London, SE5 9RS, UK. Tel./Fax: +44 2032993397; E-mail: dimitrios.bogdanos@kcl.ac.uk; http://www.bogdanoslab.com.
}

\section{Introduction}

The aetiology of primary biliary cirrhosis (PBC), an immune mediated and potentially fatal cholestatic liver disease, remains unsolved [1-3]. Genetic, infectious and environmental factors have been considered important for the development of the disease [4-10]. Support for the implication of environmental factors has been provided by case-control or large epidemiological studies [11-22]. Immunological investigations in biological material obtained from patients at early stages of the disease, and studies in experimental models resembling the human disease have revealed the pathogenic potential of specific environmental agents [10,23,24]. This review will discuss the findings of epidemiologi- 
cal, clinical and experimental studies investigating environmental factors which may contribute to the development of primary biliary cirrhosis.

\section{General considerations}

In looking for the causes of PBC, a major issue is the relative contribution of genetics and environment [1, $25,26]$. The tabula rasa (Latin for blank slate) view has swung back and forth over time with regard to the relative contribution of nurture (i.e. environment) $v s$ nature (i.e. genes) in the development of PBC. The proponents of the thesis that environmental factors dominate the pathogenic processes determining the disease's induction have based their arguments on the findings of a series of studies failing to identify a strong genetic basis. Thus, several independent studies have shown over the years a weak association of specific HLA class I or II genes with disease susceptibility [4,27]. This is different from other autoimmune diseases affecting the liver, as in the case of autoimmune hepatitis which shows a strong association with the HLA DR3 and DR4, or other autoimmune diseases like insulin dependent diabetes, multiple sclerosis and rheumatoid arthritis [2832]. The contribution of a single non-HLA gene that could predispose to the development of most PBC cases is virtually absent $[4,7,8,29]$.

\section{Migration studies and PBC}

Evidence in support of environmental factors contributing to the risk of developing PBC, is based on the observation that the risk in migrants is adjusted to, and correlates with the risk of the population into which they move [15,33-35]. An example of this can be found with British migrants to Australia [33,34]. In the UK, the $\mathrm{PBC}$ rate is $150-240$ cases/million compared to a much lower rate of 19 cases/million in Australia [33]. British migrants to Australia show a 3-5 times decrease in risk of developing PBC (47 cases/million) [36]. The opposite trend is seen in migrants from India to the UK, whose rate increases from 1-4 cases/million in the Indian subcontinent, to 14 cases/million in those who migrate to the UK [35]. These findings added support to the notion that affected individuals within a familial or regional group that has a high PBC prevalence, are exposed to a common environmental factor which triggers or contributes to the development of PBC. The interpretation of the epidemiological studies needs to be treated with caution due to methodological constraints and the significant intra- and inter-variability between studies. Nevertheless, environmental factors such as viruses, bacteria, chemicals, drugs, or xenobiotics may indeed play a role in the development of the disease [1, $3,9,23,37-50]$. The expectation is that these environmental factors would be absent in regions or populations of low PBC prevalence, or that exposure to them is minimal. On the other hand, regions with a high incidence of $\mathrm{PBC}$ would have an increased exposure to these environmental factors via a common media, such as air, soil, or water.

\section{Familial and non-familial clustering of cases with PBC}

Evidence in support of environmental and genetic factors in relation to risk for developing PBC has been developed from familial studies [51-53]. One study of familial PBC based in the Japanese city of Hiroshima found that the relative risk of a first degree relative was 50 to 100 times higher than compared to the general population [54]. This study involved 18 cases of PBC which were derived from eight different families in which more than one family member had a history of PBC. It frequently included mothers and daughters (4 families), sisters (1 family), and intriguingly also included brothers and sisters ( 2 families) and a motherdaughter-son (1 family) [54]. A subsequent study has also estimated that the prevalence of PBC among atomic bomb survivors in Nagasaki was much higher (792 per million women) than that reported for the general population in Japan, suggesting that environmental factors, including radiation exposure, may predispose to PBC [55]. Another study from the North-East of England also showed an increase in relative risk of developing $\mathrm{PBC}$, with siblings showing an increased risk of 10.5 [53]. This level of risk is similar to that found in other autoimmune diseases.

Two shared factors between affected individuals should be examined when looking at familial clustering of a disease: genes and environment. These two factors are likely to play a role individually, or combined in disease clusters. Although genetics are more commonly associated with a familial disease, commonly stated evidence in support of environmental factors comes from the timing of disease onset, in that the disease tends to occur at the same time or within a short period of time from the diagnosis of the first case. However, this is not entirely correct. When a patient is diagnosed with 
PBC, screening of relatives for autoantibodies and liver biochemical profiles is advised. It is often this screening that detects PBC cases which may be asymptomatic at the time. That is to say, that early screening often detects relatives (usually mothers, sisters, or daughters) with PBC, as opposed to symptomatic clinical presentation. Further evidence in support of an environmental factor in these familial clusters is found when examining unrelated, but affected individuals who share the same environment. Douglas and Finlayson report a mother and daughter affected by PBC, as well as a close family friend [52]. In that case, the mother and family friend developed PBC within 21 months of the daughter's death from PBC [52]. Another PBC cluster was reported in six women living in two cities in Alaska, where three of the women worked together as phone operators for several years [51]. Yet another report involves two women in a German town, both with a 20 year history of deranged liver function tests, who developed PBC within two years of each other [56]. These two women were found to share common genetic factors, as well as environmental. Genetically, they shared alleles A2, B51, DR4, DR8 and DR53 [56]. Environmentally, they shared the same desk at school from ages six to ten, and were lifelong friends [56].

\section{Nature vs nurture: The twins study}

To disentangle the effects of genes (and indirectly of the environment), Selmi et al. performed a twins study [6]. These investigators identified 16 pairs of twins within a 1400-family cohort, including 8 sets each of monozygotic (all female) and dizygotic twins ( 4 female and 4 female-male pairs). In 5 of 8 sets of the monozygotic twins, both individuals had PBC (0.63 concordance). The argument that in cases that genes were the only risk factors, someone would expect that all monozygotic pairs would develop the disease is not valid. In fact, the concordance rate of PBC in identical twins is among the highest reported for any autoimmune disease.

Among the 8 dizygotic twin pairs, however, none were concordant for PBC [6]. Interestingly, the age at onset of disease was similar in 4 of the 5 concordant monozygotic twin pairs. In the fifth pair, the diagnosis of PBC was made with a 5 year gap. In one case, the twins had variant clinical behaviour, with one listed for liver transplantation 8 years after presentation and the other showing no sings of advanced liver disease for more than 13 years of follow-up [6]. Patients with PBC can have a prolonged sub-clinical period of the disease $[3,57]$. Thus, the possibility that the 3 disease-free women (aged 55, 60 and 61 at the time of the report) of the discordant for PBC monozygotic pairs may develop full-blown disease can not be excluded [57]. The fact that the disease affected only one of the dizygotic twins is of interest. Four of them were men and PBC in men is infrequent. The overall discordance for PBC in 11 (3 monozygotic and 8 dizygotic pair sets) is puzzling. Such findings are against the role of environment in the development of PBC. If environmental factors played a role in PBC development, one would expect some concordance in the non-genetically identical dizygotic twins who share environmental factors. This would be especially true in female-female twin pairs, but could be questionable in male-female pairs due to the low preponderance of PBC in males. Dizygotic pairs do not share the same genes and therefore this discordance is more in support of genetic involvement.

\section{The Triger who triggered the water-contaminant hypothesis as a PBC trigger}

Perhaps the most significant contribution to the hypothesis of an environmental trigger of PBC came from a 1980 study by David Triger, a 38 year old physician and Senior Lecturer in Medicine at Royal Hallamshire Hospital [21]. This study, published in the British Medical Journal, noted a high prevalence of PBC in the city of Sheffield in Northern England (a total of 34 cases, giving a prevalence of 54 cases/million) [21]. Triger suggested a potential environmental cause of this increased prevalence, possibly due to the heavy industrialisation of the city with coal mines and steel smelting factories. Clusters of PBC were found in districts of the city with prevalence rates too high to be attributed to chance [21]. Examination of the HLA subtypes and careful questioning ruled out the possibility that these clusters were familial. Atmospheric pollution was implicated due to the large scale smelting works, but this was ruled out as a potential trigger, as surrounding areas did not report clusters of $\mathrm{PBC}$. Triger demonstrated that $30(88 \%)$ of all PBC cases received their water supply from a single reservoir, known as the Rivelin reservoir (this was one of six reservoirs supplying the city at the time) [21]. The population supplied by this reservoir showed a prevalence of PBC ten times higher than the population supplied by other reservoirs. The remaining 4 PBC cases received their water supply from the remaining five reservoirs, which provided $60 \%$ of the 
cities water. In order for the water supply to be implicated, it would need to be established that affected individuals had a lengthy exposure to a common water supply. Triger notes that 26 of the 34 patients lived in Sheffield their entire lives, with the remaining eight having lived there for an average of 49 years before presenting with PBC [21]. The average amount of time in the same house was 20 years, with the mean period of time spent in the area supplied by the same reservoir was 42 years.

With the above data in mind, Triger set out to examine the cities water supply for aluminium and other metals. Aluminium was selected based on a previous report which noted its high concentrations in Sheffield's water, and implicated this with cases of bone disease and encephalopathy due to haemodialysis for chronic renal failure. Triger found high aluminium concentrations in three reservoirs, one of which was the Rivelin reservoir. This finding pointed away from aluminium as a potential trigger/cause for PBC, as the other two reservoirs did not supply a population with a high PBC prevalence [21]. No other significant findings were found in relation to zinc, copper, and several other metals. The only significant finding was that the Rivelin reservoir has particularly soft water (total and non-carbonate), and lower concentrations of fluoride. It remained unclear as to whether these findings had any significance in the pathogenesis of PBC. In addition to the reservoirs, Triger also examined the water delivery system, as contamination along this route was also a possibility [21]. This was performed by analysing random water samples from the taps of patients and controls homes. A 300 fold variation in copper concentrations was found from one house to another, in the patient and control groups. The study by Triger, reporting a clustering of cases and their temporal association with a specific water supply system has formulated a series of subsequent studies aiming at investigating whether clusters of PBC do really exist, and whether there is a waterborne risk factor which can be identified. Another study of the epidemiology of PBC noted an urban clustering of this disease in the Greater Nottingham area, UK but no specific risk factor has been identified on analysis of water [58]. Neither the Sheffield nor the Nottingham studies have published subsequent reports in their series and the possibility that clustering may have been coincidental has been considered. This has been strengthened by studies of patients with PBC in Ontario, Canada which were unable to identify clusters of the disease [59].

\section{Triggers of PBC: The Newcastle 'hot spots'}

Epidemiological studies of PBC have been done extensively in the city of Newcastle, perhaps more so than in any other population $[11,12,14,16,17]$. Much like Sheffield, Newcastle was a heavily industrialised city, especially in regards to coal mining. Prince et al. noted a high prevalence of PBC in the North-East of England, with 32.2 new cases per million, and a prevalence of 251 cases per million (based on data from 1994) [12]. In women over the age of 40, the PBC prevalence was 940 per million. The study included 770 patients with PBC, and showed a significant non-random spatial distribution of cases. Three well defined clusters of high PBC prevalence were found [12]. Ten cases were noted in one cluster, which is located in a suburb of Newcastle and North Tyneside, with an area of $1.4 \mathrm{~km}^{2}$ giving a case density of $7.1 / \mathrm{km}^{2}$. The remaining two consisted of eight cases in a $0.75 \mathrm{~km}^{2}$ area $(10.7$ cases per $\mathrm{km}^{2}$ ), and six cases in a $1 \mathrm{~km}^{2}$ area [12]. Familial clustering was ruled out, and there did not appear to be any other commonality between the clusters. This study noted that there was no association with the water supply, which came from a variety of sources, but unlike the study by Triger, the Newcatle group did not test the water supply [12]. The clustering of patients with PBC has led the Newcastle group to suggest that an unidentified environmental factor may explain the higher prevalence and clustering of PBC in former industrial and/or coal mining areas. As these regions are no longer heavily industrialised, one would expect the incidence of PBC to decrease, as the exposure to these environmental triggers is reduced or absent. However, this is not the case, and there is still a significant prevalence of $\mathrm{PBC}$ in these regions. If an environmental trigger related to industry and/or coal mining exists, it could be hypothesised that regions which are still currently involved in coal mining (such as in parts of Canada, Arizona, and China) will show a higher prevalence of PBC in the future. Whether or not this is the case remains to be seen.

Another factor in favour of an environmental trigger is the prevalence of men with PBC in the clusters, compared to the general (non-clustered) prevalence of PBC. As the coal mining and steel working industries were heavily employed by men in these regions, there would therefore be a higher rate of exposure to environmental factors, and therefore a higher rate of $\mathrm{PBC}$ in men than is normally found. Although the studies by Prince et al and Triger note an overwhelmingly higher preponderance of females affected with PBC, both 
studies include affected men, at a rate higher than that of the general (non-clustered) $\mathrm{PBC}$ population. In other words, the prevalence of $\mathrm{PBC}$ among males remains low, but is higher than expected in some clusters.

Emerging data from the Newcastle group may help us to better understand the relative contribution of environmental factors in the disease pathogenesis [11]. McNally et al. analyzed for space-time clustering using population-based data from northeast England over a defined period of seven years (from 1987-2003) [11]. Space-clustering is observed when excess cases of a given disease can be identified within restricted geographical areas at limited periods of time. Analysis of their data suggests space-clustering of PBC which can not be attributed to variations in population density.

These findings indicate the possible involvement of a geographically widespread, but transient, causative agent and are consistent with "either a very short "lag time" between exposure to an etiologically relevant agent and subsequent diagnosis or a longer, but relatively constant, "lag time" between exposure and diagnosis' [11].

\section{From Newcastle to New York}

In 2006, Ala et al. published a study evaluating the relationship of environmental factors with PBC [22]. This study showed that the prevalence of PBC patients listed for transplantation was increased near superfund toxic waste sites in New York State. Additionally, a statistically significant PBC patient cluster, including both patients not listed for transplantation and those listed for transplantation, was identified in Staten Island near a superfund waste site contaminated with volatile aromatic hydrocarbons and trichloroethylene [22]. The precise mechanism(s) by which the proximity to such sites may increase exposure to these toxins is not clear. The Sheffield study speculated that differences in regional water supplies might account for clustering. According to Ala et al., $85 \%$ of ground water near superfund toxic waste sites in New York State is contaminated, but the residents do not rely on groundwater as a water supply [22]. This has led them to suggest that inhalation of volatile organic compounds (e.g., benzene) and particle bound chlorinated hydrocarbons released into the air from these sites, is a more plausible method of exposure. This view is supported by large epidemiological studies of risk factors for PBC performed in the UK and USA, reporting that cigarette smoking (another source of benzene) is associated with PBC $[11,18$,
19]. Of relevance to the New York study, Amano et al. reported that halogenated forms of benzene may mimic the lipoylated PBC autoantigen epitope, and indicated that air-borne volatile organic compounds such as benzene may indeed contribute to the immunopathogenesis of PBC [23,24].

The higher prevalence of cases with primary sclerosing cholangitis (an immune mediated cholestatic disease which does not overlap with PBC) near toxic waste sites suggests that exposure to toxins is not specific for PBC [22].

\section{Xenobiotics vs $\operatorname{Xeno}(\mathbf{P}) b(C)$ iotics}

Although specific environmental compounds causing PBC have not been clearly identified, xenobiotics are now emerging as compounds that could possibly narrow the gap between environmental exposure and PBC pathogenesis $[1,26]$. This is not overly surprising, as xenobiotics have been linked with autoimmune disease, so much that specific xenobiotics are linked to specific autoimmune diseases. Xenobiotics are capable of altering or forming complexes with self or non-self proteins. This induces a change in the proteins molecular structure, which may cause an immune response, and subsequent cross-recognition with mitochondrial autoepitopes. This process is similar to that of molecular mimicry both in concept, as well as the transient presence of the triggering molecule/organism [60,61]. The list of exogenous compounds is long and complex, but includes common items such as detergents and cosmetics, as well as polluting materials [62]. Being the primary detoxification organ, the hepatocytes and the biliary epithelial cells are prime targets of chemical compounds. The working hypothesis is that modifications of the lipoylated major mitochondrial autoantigen could trigger the production of autoantibodies. A series of recent studies from the group of Eric Gershwin have provided data to support this view; their findings are reviewed elsewhere $[1,10,23,24,63]$. Hence, it has been shown that that 2-nonynoic acid is recognized by $\mathrm{PBC}$ sera with high affinity, and indicate that this compound is able to induce cholangiopathy in immunised mice [1, $10,23,24,63]$. This xenobiotic is found in cosmetics and nail polish, which may give a possible clue as to the female preponderance of the disease.

\section{Novosphingobium aromaticivorans: The missing environmental link?}

The same group of investigators has provided sero- 
logical and molecular data suggesting that a ubiquitous xenobiotic-metabolizing Gram-negative bacterium, Novosphingobium aromaticivorans, is a potential trigger for the induction of PBC [46]. This bacterium contains two proteins which share amino acid sequences to the immunodominant epitope of PDCE2 [46]. It is also capable of metabolizing organic compounds such as oestrogens, which is intriguing given the female preponderance of PBC [64]. N. aromaticivorans was found in $25 \%$ of human faecal samples tested. Contributing to this is the study by Mattner et al, who found that $N$. aromaticivorans was capable of inducing PBC-specific anti-mitochondrial antibodies in mice following immunization [65]. These mice were also shown to have PBC-like bile duct lesions [65].

\section{PBC triggering agents may be everywhere - Concluding remarks}

Thirty years after the Sheffield study, the agent contained in the Rivelin reservoir which could account for the development of PBC remains unknown. Much effort has been put into identifying chemicals or other compounds that are contained in the water, but none have looked for an infectious component. This would need to be ubiquitous in the environment (soil, water) and pathogenic to susceptible hosts. The idea that exposure to certain environmental factor(s), not harmful per se, could result in the breakdown of immunological tolerance and the induction of disease-specific destruction, cannot be discouraged. The number of studies investigating the role of specific environmental triggers has increased considerably, and may lead to a more conclusive result in the not too distant future. There is no doubt that the triggering agents of PBC can be everywhere, from water reservoirs and coal mining areas, to superfund waste disposal sites, from Sheffield and Newcastle to New York. We may not yet know them, but we hope that we will find them.

\section{In Memoriam}

Professor David R. Triger, DPhil, FRCP. 1941-1993.

\section{References}

[1] M.E. Gershwin and I.R. Mackay, The causes of primary biliary cirrhosis: Convenient and inconvenient truths, Hepatology 47 (2008), 737-745.
[2] D. Vergani, D.P. Bogdanos and H. Baum, Unusual suspects in primary biliary cirrhosis, Hepatology 39 (2004), 38-41.

[3] M.M. Kaplan and M.E. Gershwin, Primary biliary cirrhosis, N Engl J Med 353 (2005), 1261-1273.

[4] P.T. Donaldson, A. Baragiotta, M.A. Heneghan, A. Floreani, C. Venturi, J.A. Underhill, D.E. Jones, O.F. James and M.F. Bassendine, HLA class II alleles, genotypes, haplotypes, and amino acids in primary biliary cirrhosis: a large-scale study, Hepatology 44 (2006), 667-674.

[5] P. Invernizzi, M. Miozzo, P.M. Battezzati, I. Bianchi, F.R. Grati, G. Simoni, C. Selmi, M. Watnik, M.E. Gershwin and M. Podda, Frequency of monosomy $\mathrm{X}$ in women with primary biliary cirrhosis, Lancet 363 (2004), 533-535.

[6] C. Selmi, M.J. Mayo, N. Bach, H. Ishibashi, P. Invernizzi, R.G. Gish, S.C. Gordon, H.I. Wright, B. Zweiban, M. Podda and M.E. Gershwin, Primary biliary cirrhosis in monozygotic and dizygotic twins: genetics, epigenetics, and environment, Gastroenterology 127 (2004), 485-492.

[7] B.D. Juran, E.J. Atkinson, J.J. Larson, E.M. Schlicht, X. Liu, E.J. Heathcote, G.M. Hirschfield, K.A. Siminovitch and K.N. Lazaridis, Carriage of a tumor necrosis factor polymorphism amplifies the cytotoxic T-lymphocyte antigen 4 attributed risk of primary biliary cirrhosis: evidence for a gene-gene interaction, Hepatology 52, 223-229.

[8] G.M. Hirschfield, X. Liu, C. Xu, Y. Lu, G. Xie, Y. Lu, X. Gu, E.J. Walker, K. Jing, B.D. Juran, A.L. Mason, R.P. Myers, K.M. Peltekian, C.N. Ghent, C. Coltescu, E.J. Atkinson, E.J. Heathcote, K.N. Lazaridis, C.I. Amos and K.A. Siminovitch, Primary biliary cirrhosis associated with HLA, IL12A, and IL12RB2 variants, N Engl J Med 360 (2009), 2544-2555.

[9] D.P. Bogdanos, K. Choudhuri and D. Vergani, Molecular mimicry and autoimmune liver disease: virtuous intentions, malign consequences, Liver 21 (2001), 225-232.

[10] C. Selmi, F. Meda, A. Kasangian, P. Invernizzi, Z. Tian, Z. Lian, M. Podda and M.E. Gershwin, Experimental evidence on the immunopathogenesis of primary biliary cirrhosis, Cell Mol Immunol 7, 1-10.

[11] R.J. McNally, S. Ducker and O.F. James, Are transient environmental agents involved in the cause of primary biliary cirrhosis? Evidence from space-time clustering analysis, Hepatology 50 (2009), 1169-1174.

[12] M.I. Prince, A. Chetwynd, P. Diggle, M. Jarner, J.V. Metcalf and O.F. James, The geographical distribution of primary biliary cirrhosis in a well-defined cohort, Hepatology 34 (2001), 1083-1088.

[13] D. Howel, C.M. Fischbacher, R.S. Bhopal, J. Gray, J.V. Metcalf, O.F. James, An exploratory population-based casecontrol study of primary biliary cirrhosis, Hepatology $\mathbf{3 1}$ (2000), 1055-1060.

[14] O.F. James, R. Bhopal, D. Howel, J. Gray, A.D. Burt and J.V. Metcalf, Primary biliary cirrhosis once rare, now common in the United Kingdom? Hepatology 30 (1999), 390-394.

[15] J. Metcalf and O. James, The geoepidemiology of primary biliary cirrhosis, Semin Liver Dis 17 (1997), 13-22.

[16] J.V. Metcalf, R.S. Bhopal, J. Gray, D. Howel and O.F. James, Incidence and prevalence of primary biliary cirrhosis in the city of Newcastle upon Tyne, England, Int J Epidemiol 26 (1997), 830-836.

[17] M.I. Prince, S.J. Ducker and O.F. James, Case-control studies of risk factors for primary biliary cirrhosis in two United Kingdom populations, Gut 59, 508-512.

[18] M.E. Gershwin, C. Selmi, H.J. Worman, E.B. Gold, M. Watnik, J. Utts, K.D. Lindor, M.M. Kaplan and J.M. Vierling, Risk factors and comorbidities in primary biliary cirrhosis: a 
controlled interview-based study of 1032 patients, Hepatology 42 (2005), 1194-1202.

[19] A. Parikh-Patel, E.B. Gold, H. Worman, K.E. Krivy and M.E. Gershwin, Risk factors for primary biliary cirrhosis in a cohort of patients from the united states, Hepatology 33 (2001), 1621.

[20] S.F. Bruggraber, P.S. Leung, K. Amano, C. Quan, M.J. Kurth, M.H. Nantz, G.D. Benson, J. Van de Water, V. Luketic, T.E. Roche, A.A. Ansari, R.L. Coppel and M.E. Gershwin, Autoreactivity to lipoate and a conjugated form of lipoate in primary biliary cirrhosis, Gastroenterology 125 (2003), 1705-1713.

[21] D.R. Triger, Primary biliary cirrhosis: an epidemiological study, Br Med J 281 (1980), 772-775.

[22] A. Ala, C.M. Stanca, M. Bu-Ghanim, I. Ahmado, A.D. Branch, T.D. Schiano, J.A. Odin and N. Bach, Increased prevalence of primary biliary cirrhosis near Superfund toxic waste sites, Hepatology 43 (2006), 525-531.

[23] K. Amano, P.S. Leung, R. Rieger, C. Quan, X. Wang, J. Marik, Y.F. Suen, M.J. Kurth, M.H. Nantz, A.A. Ansari, K.S. Lam, M. Zeniya, E. Matsuura, R.L. Coppel and M.E. Gershwin, Chemical xenobiotics and mitochondrial autoantigens in primary biliary cirrhosis: identification of antibodies against a common environmental, cosmetic, and food additive, 2-octynoic acid, J Immunol 174 (2005), 5874-5883.

[24] K. Amano, P.S. Leung, Q. Xu, J. Marik, C. Quan, M.J. Kurth, M.H. Nantz, A.A. Ansari, K.S. Lam, M. Zeniya, R.L. Coppel and M.E. Gershwin, Xenobiotic-induced loss of tolerance in rabbits to the mitochondrial autoantigen of primary biliary cirrhosis is reversible, J Immunol 172 (2004), 6444-6452.

[25] D.E. Jones, Pathogenesis of primary biliary cirrhosis, Gut $\mathbf{5 6}$ (2007), 1615-1624.

[26] C. Selmi and M.E. Gershwin, The role of environmental factors in primary biliary cirrhosis, Trends Immunol 30 (2009), 415-420.

[27] D.E. Jones and P.T. Donaldson, Genetic factors in the pathogenesis of primary biliary cirrhosis, Clin Liver Dis 7 (2003), 841-864.

[28] D. Vergani, M.S. Longhi, D.P. Bogdanos, Y. Ma and G. Mieli-Vergani, Autoimmune hepatitis, Semin Immunopathol 31 (2009), 421-435.

[29] P.T. Donaldson, Genetics of liver disease: immunogenetics and disease pathogenesis, Gut 53 (2004), 599-608.

[30] J.A. Bluestone, K. Herold and G. Eisenbarth, Genetics, pathogenesis and clinical interventions in type 1 diabetes, Nature 464, 1293-1300.

[31] S.V. Ramagopalan, J.C. Knight and G.C. Ebers, Multiple sclerosis and the major histocompatibility complex, Curr Opin Neurol 22 (2009), 219-225.

[32] V. Taneja and C.S. David, Role of HLA class II genes in susceptibility/resistance to inflammatory arthritis: studies with humanized mice, Immunol Rev 233, 62-78.

[33] R.G. Watson, P.W. Angus, M. Dewar, B. Goss, R.B. Sewell and R.A. Smallwood, Low prevalence of primary biliary cirrhosis in Victoria, Australia. Melbourne Liver Group, Gut 36 (1995), 927-930.

[34] S. Sood, P.J. Gow, J.M. Christie and P.W. Angus, Epidemiology of primary biliary cirrhosis in Victoria, Australia: high prevalence in migrant populations, Gastroenterology 127 (2004), 470-475.

[35] A.C. Anand, E. Elias and J.M. Neuberger, End-stage primary biliary cirrhosis in a first generation migrant south Asian population, Eur J Gastroenterol Hepatol 8 (1996), 663-666.

[36] C. Selmi, P. Invernizzi, E.B. Keeffe, R.L. Coppel, M. Podda, L. Rossaro, A.A. Ansari and M.E. Gershwin, Epidemiology and pathogenesis of primary biliary cirrhosis, J Clin Gastroenterol 38 (2004), 264-271.

[37] C. Selmi, P. Invernizzi, M. Zuin, M. Podda and M.E. Gershwin, Genetics and geoepidemiology of primary biliary cirrhosis: following the footprints to disease etiology, Semin Liver Dis 25 (2005), 265-280.

[38] D.P. Bogdanos, H. Baum, A. Grasso, M. Okamoto, P. Butler, Y. Ma, E. Rigopoulou, P. Montalto, E.T. Davies, A.K. Burroughs and D. Vergani, Microbial mimics are major targets of crossreactivity with human pyruvate dehydrogenase in primary biliary cirrhosis, J Hepatol 40 (2004), 31-39.

[39] D.P. Bogdanos, H. Baum, F. Gunsar, D. Arioli, D. Polymeros, Y. Ma, A.K. Burroughs and D. Vergani, Extensive homology between the major immunodominant mitochondrial antigen in primary biliary cirrhosis and Helicobacter pylori does not lead to immunological cross-reactivity, Scand J Gastroenterol 39 (2004), 981-987.

[40] D.P. Bogdanos, H. Baum, M. Okamoto, P. Montalto, U.C. Sharma, E.I. Rigopoulou, J. Vlachogiannakos, Y. Ma, A.K. Burroughs and D. Vergani, Primary biliary cirrhosis is characterized by IgG3 antibodies cross-reactive with the major mitochondrial autoepitope and its Lactobacillus mimic, Hepatology 42 (2005), 458-465.

[41] D.P. Bogdanos, H. Baum, U.C. Sharma, A. Grasso, Y. Ma, A.K. Burroughs and D. Vergani, Antibodies against homologous microbial caseinolytic proteases $\mathrm{P}$ characterise primary biliary cirrhosis, J Hepatol 36 (2002), 14-21.

[42] D.P. Bogdanos, A. Koutsoumpas, H. Baum and D. Vergani, Borrelia Burgdorferi: a new self-mimicking trigger in primary biliary cirrhosis, Dig Liver Dis 38 (2006), 781-782; author reply $782-783$.

[43] D.P. Bogdanos, A. Pares, H. Baum, L. Caballeria, E.I. Rigopoulou, Y. Ma, A.K. Burroughs, J. Rodes and D. Vergani, Disease-specific cross-reactivity between mimicking peptides of heat shock protein of Mycobacterium gordonae and dominant epitope of E2 subunit of pyruvate dehydrogenase is common in Spanish but not British patients with primary biliary cirrhosis, J Autoimmun 22 (2004), 353-362.

[44] D.P. Bogdanos and D. Vergani, Origin of cross-reactive autoimmunity in primary biliary cirrhosis, Liver Int 26 (2006), 633-635.

[45] D.P. Bogdanos and D. Vergani, Bacteria and primary biliary cirrhosis, Clin Rev Allergy Immunol 36 (2009), 30-39.

[46] C. Selmi, D.L. Balkwill, P. Invernizzi, A.A. Ansari, R.L. Coppel, M. Podda, P.S. Leung, T.P. Kenny, J. Van De Water, M.H. Nantz, M.J. Kurth and M.E. Gershwin, Patients with primary biliary cirrhosis react against a ubiquitous xenobioticmetabolizing bacterium, Hepatology 38 (2003), 1250-1257.

[47] L. Xu, Z. Shen, L. Guo, B. Fodera, A. Keogh, R. Joplin, B. O’Donnell, J. Aitken, W. Carman, J. Neuberger and A. Mason, Does a betaretrovirus infection trigger primary biliary cirrhosis? Proc Natl Acad Sci U S A 100 (2003), 8454-8459.

[48] A.S. Abdulkarim, L.M. Petrovic, W.R. Kim, P. Angulo, R.V. Lloyd and K.D. Lindor, Primary biliary cirrhosis: an infectious disease caused by Chlamydia pneumoniae? J Hepatol 40 (2004), 380-384.

[49] M.J. Goo, M.R. Ki, H.R. Lee, I.H. Hong, J.K. Park, H.J. Yang, D.W. Yuan, O.K. Hwang, S.H. Do, S.E. Yoo and K.S. Jeong, Primary biliary cirrhosis, similar to that in human beings, in a male C57BL/6 mouse infected with Helicobacter Pylori, Eur J Gastroenterol Hepatol 20 (2008), 1045-1048.

[50] P.S. Leung, O. Park, S. Matsumura, A.A. Ansari, R.L. Coppel and M.E. Gershwin, Is there a relation between Chlamydia 
infection and primary biliary cirrhosis? Clin Dev Immunol 10 (2003), 227-233.

[51] S. Abu-Mouch, C. Selmi, G.D. Benson, T.P. Kenny, P. Invernizzi, M. Zuin, M. Podda, L. Rossaro and M.E. Gershwin, Geographic clusters of primary biliary cirrhosis, Clin Dev Immunol 10 (2003), 127-131.

[52] J.G. Douglas and N.D. Finlayson, Are increased individual susceptibility and environmental factors both necessary for the development of primary biliary cirrhosis? Br Med J 2 (1979), 419-420.

[53] D.E. Jones, F.E. Watt, J.V. Metcalf, M.F. Bassendine and O.F. James, Familial primary biliary cirrhosis reassessed: a geographically-based population study, J Hepatol 30 (1999), 402-407.

[54] K. Tsuji, Y. Watanabe, J. Van De Water, T. Nakanishi, G. Kajiyama, A. Parikh-Patel, R. Coppel and M.E. Gershwin, Familial primary biliary cirrhosis in Hiroshima, J Autoimmun 13 (1999), 171-178.

[55] K. Ohba, K. Omagari, H. Kinoshita, H. Soda, J. Masuda, H. Hazama, M. Tagawa, T. Hata, H. Nakamura, I. Murata and S. Kohno, Primary biliary cirrhosis among atomic bomb survivors in Nagasaki, Japan, J Clin Epidemiol 54 (2001), 845-850.

[56] M. von Mach, Primary biliary cirrhosis in classmates: coincidence of enigmatic environmental influence? EXCLI 1 (2002), $1-7$.

[57] J. Neuberger, Primary biliary cirrhosis, Lancet 350 (1997), 875-879.

[58] J. Mayberry, J. Giggs and H. Smart, Urban clustering of pri- mary biliary cirrhosis, Gut 27 (1986), A1265.

[59] H. Witt-Sullivan, J. Heathcote, K. Cauch, L. Blendis, C. Ghent, A. Katz, R. Milner, S.C. Pappas, J. Rankin and I.R. Wanless, The demography of primary biliary cirrhosis in Ontario, Canada, Hepatology 12 (1990), 98-105.

[60] D.P. Bogdanos, G. Mieli-Vergani and D. Vergani, Virus, liver and autoimmunity, Dig Liver Dis 32 (2000), 440-446.

[61] M.B. Oldstone, Molecular mimicry and autoimmune disease, Cell 50 (1987), 819-820.

62] S.A. Long, C. Quan, J. Van de Water, M.H. Nantz, M.J. Kurth, D. Barsky, M.E. Colvin, K.S. Lam, R.L. Coppel, A. Ansari and M.E. Gershwin, Immunoreactivity of organic mimeotopes of the E2 component of pyruvate dehydrogenase: connecting xenobiotics with primary biliary cirrhosis, J Immunol 167 (2001), 2956-2963.

[63] P.S. Leung, T. Iwayama, R.L. Coppel and M.E. Gershwin, Site-directed mutagenesis of lysine within the immunodominant autoepitope of PDC-E2, Hepatology 12 (1990), 13211328.

[64] D. Alvaro, P. Invernizzi, P. Onori, A. Franchitto, A. De Santis, A. Crosignani, R. Sferra, S. Ginanni-Corradini, M.G. Mancino, M. Maggioni, A.F. Attili, M. Podda and E. Gaudio, Estrogen receptors in cholangiocytes and the progression of primary biliary cirrhosis, J Hepatol 41 (2004), 905-912.

[65] J. Mattner, P.B. Savage, P. Leung, S.S. Oertelt, V. Wang, O. Trivedi, S.T. Scanlon, K. Pendem, L. Teyton, J. Hart, W.M. Ridgway, L.S. Wicker, M.E. Gershwin and A. Bendelac, Liver autoimmunity triggered by microbial activation of natural killer T cells, Cell Host Microbe 3 (2008), 304-315. 


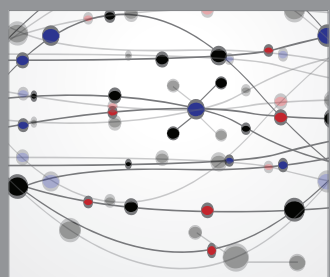

The Scientific World Journal
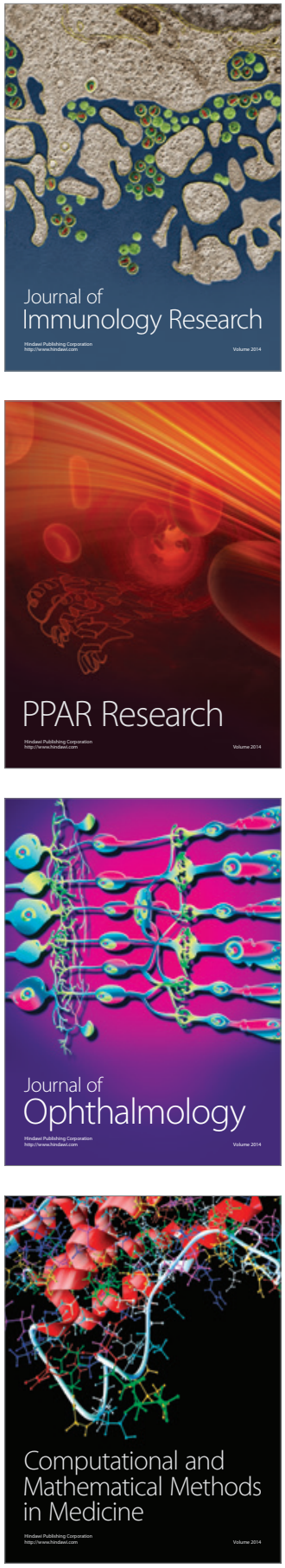

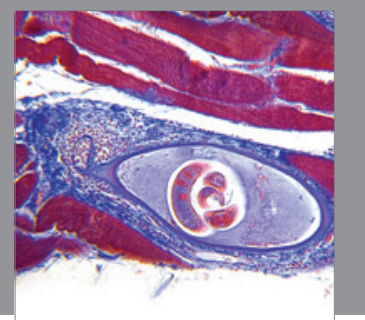

Gastroenterology

Research and Practice
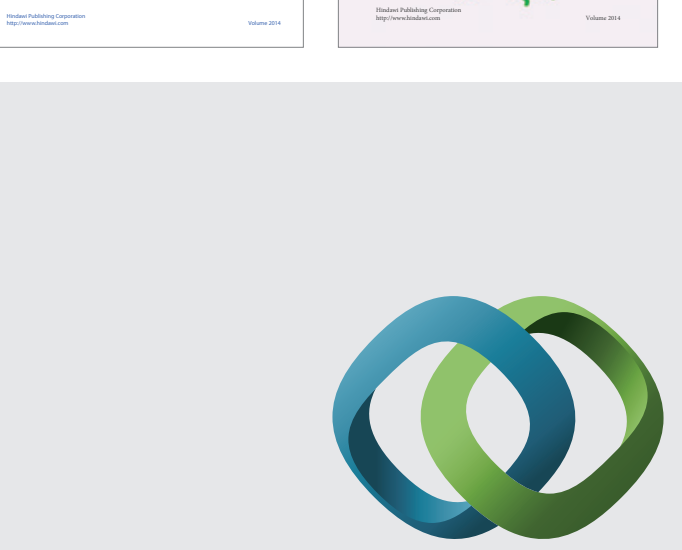

\section{Hindawi}

Submit your manuscripts at

http://www.hindawi.com
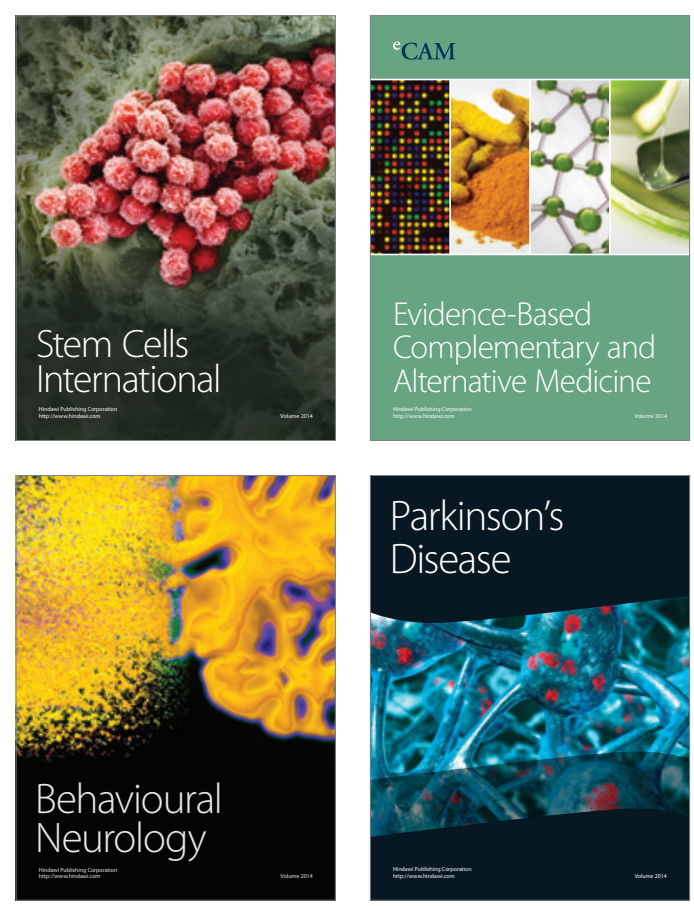

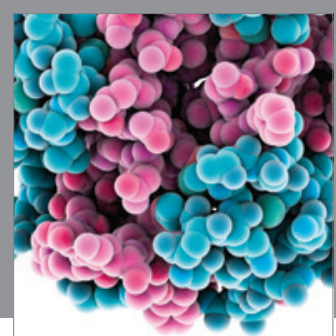

Journal of
Diabetes Research

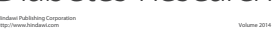

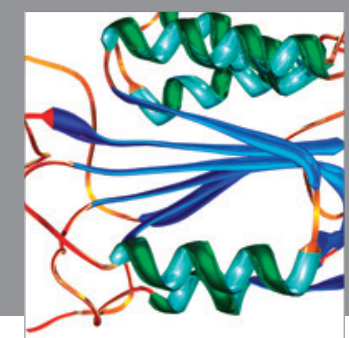

Disease Markers
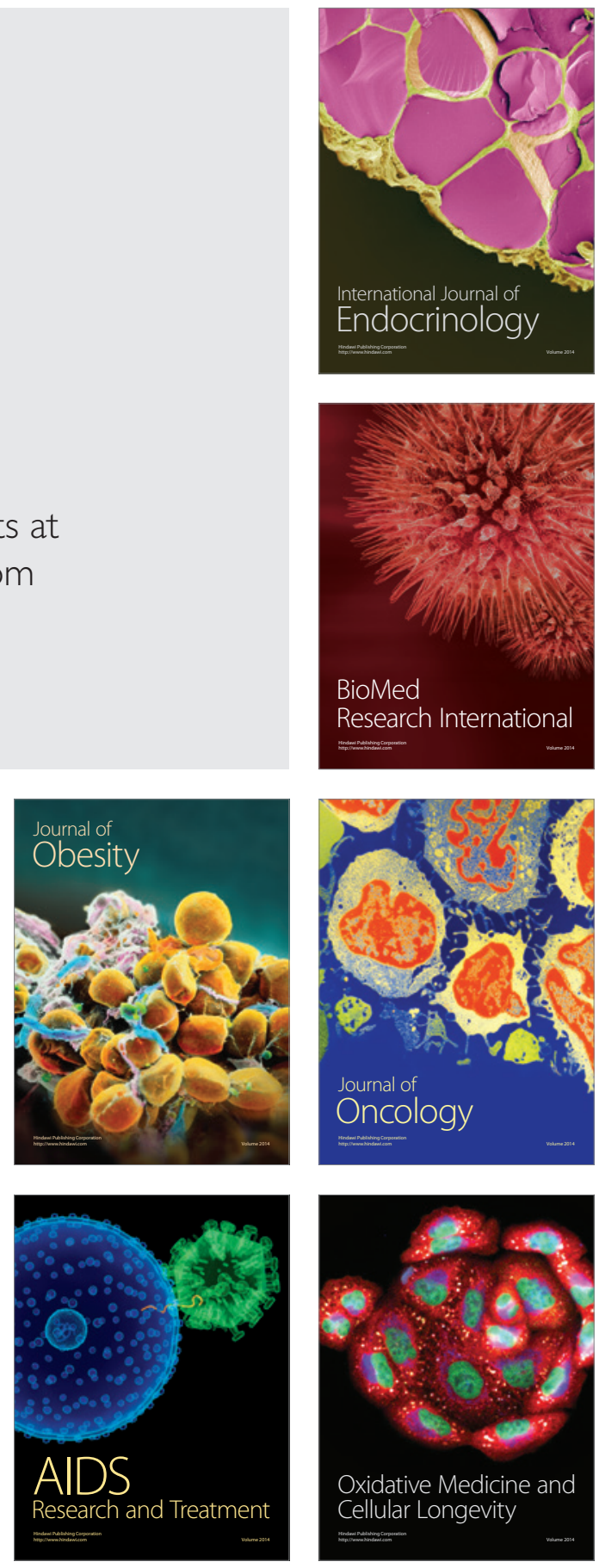